\title{
Long term result of silicone oil versus gas tamponade in the treatment of traumatic macular holes
}

\author{
Hammouda H Ghoraba' \\ Amin F Ellakwa ${ }^{2}$ \\ Ali A Ghali ${ }^{3}$ \\ 'Tanta University, Magrabi \\ Eye Hospital, Tanta, Egypt; \\ ${ }^{2}$ Menoufiya University, \\ Shebin Elkom, Menoufiya, \\ Egypt; ${ }^{3}$ Alazhar University, \\ Damitta, Egypt
}

This article was published in the following Dove Press journal:

Clinical Ophthalmology

6 January 2012

Number of times this article has been viewed
Purpose: To compare the effectiveness of pars plana vitrectomy (PPV) with either silicone oil or gas tamponade for the treatment of traumatic macular holes.

Methods: A retrospective comparative study included 22 patients who were operated on by PPV for repair of traumatic macular holes with either silicone oil tamponade (nine patients) or perfluoropropane $\left(\mathrm{C}_{3} \mathrm{~F}_{8}\right)$ gas tamponade (13 patients).

Results: Twenty-two cases were reviewed to assess the anatomical and visual outcomes of surgery with silicone oil tamponade in nine cases $(40.9 \%)$ vs $14 \% \mathrm{C}_{3} \mathrm{~F}_{8}$ gas tamponade in 13 cases $(59.1 \%)$. The age of the silicone oil-treated patients ranged from 10 to 40 years (mean $27.4 \pm 11.3$ years), while that of the gas-treated patients ranged from 19 to 35 years (mean $26.54 \pm 5.68$ years). Female patients accounted for $33.3 \%$ of the silicone oil group and $30.77 \%$ of the gas-treated group. The minimal follow-up time for the silicone oil-treated group was 13 months, with a maximum of 18 months after silicone oil removal. The minimal follow-up time for the gas-treated group was 12 months and the maximum was 24 months. The rate of hole closure after the primary operation with oil tamponade was significantly lower than that with gas tamponade $(66.67 \%$ vs $92.3 \% ; P=0.022)$. With re-operations, the final rate of hole closure was higher in the gas group (100\%) than in the silicone oil group (77.8\%). The final postoperative decimal visual acuity for the gas group was significantly better than for the oil group ( 0.433 vs $0.245 ; P=0.047)$.

Conclusions: $\mathrm{C}_{3} \mathrm{~F}_{8}$ gas was a more effective tamponade than silicone oil in achieving initial closure of traumatic macular holes. Eyes receiving an oil tamponade required significantly more re-operations to achieve hole closure than did eyes undergoing a gas tamponade. Final visual acuity was better for gas-treated eyes than for silicone oil-treated eyes.

Keywords: $\mathrm{C}_{3} \mathrm{~F}_{8}$ gas, macular hole, silicone oil, trauma, vitrectomy

\section{Introduction}

Macular holes may be idiopathic, traumatic, myopic or due to other uncommon causes. ${ }^{1}$

Marked progress in the treatment of macular holes has occurred in recent years, moving from no treatment in $1989^{2}$ to a $>90 \%$ success rate in closing these holes by vitreoretinal surgery with or without adjunctive materials. ${ }^{3-8}$

Post-traumatic macular holes constitute about 5\%-10\% of all types of macular holes. They develop due to many causes including subfoveal hemorrhage, contusion necrosis and/or vitreous traction, ${ }^{9}$ and can be successfully closed with the same vitreoretinal techniques used for idiopathic macular holes. ${ }^{10-14}$
Correspondence: Amin F Ellakw Menoufiya University, Shebin

Elkom, Menoufiya, Egypt

Tel +20 I05288543

Email ellakwah@hotmail.com 
The repair of traumatic macular holes has traditionally been accomplished by vitrectomy with gas tamponade and strict face-down positioning. Many patients were unable to tolerate this difficult postoperative position requirement due to physical or medical reasons. Therefore, alternative materials to gas tamponade were developed, including silicone oil. ${ }^{1-3}$

\section{Patients and methods}

A retrospective comparative study was done from November 1998 to August 2010. During this period, 34 cases were operated upon for closure of traumatic macular holes. Twelve cases were excluded from the study due to the lack of at least 1 year's follow-up after the last surgical procedure, or the presence of associated retinal detachment. Twenty-two cases were reviewed to assess anatomical closure using optical coherence tomography (OCT) and visual outcomes after surgery with silicone oil tamponade or $14 \% \mathrm{C}_{3} \mathrm{~F}_{8}$ gas tamponade. Silicone oil was used as a tamponade in children; large holes; conditions preventing strict face-down position; or in patients unwilling to undertake the strict positioning. A thorough history from the patient was taken. Ophthalmological examination was done as follows: best corrected visual acuity using a Snellen's chart; intraocular pressure using an applanation tonometer; slit lamp examination of the anterior segment of the eye; and biomicroscopy of the posterior segment using the Goldman 3-mirror contact lens. Binocular indirect ophthalmoscopy with or without indentation was used to examine the periphery of the retina. OCT was conducted using Stratus OCT (v 4.0.7; Carl Zeiss, Meditec, Inc, Dublin, CA).

\section{Case I: traumatic macular hole and silicone oil tamponade}

Preoperative OCT of traumatic macular hole was done (Figure 1) and repeated after silicone oil removal (Figure 2).

\section{Case 2: traumatic macular hole and C3F8 tamponade}

Preoperative OCT of traumatic macular hole was done (Figure 3) and repeated after gas absorption (Figure 4).

The operative procedure was discussed in detail with all patients or their relatives and written consent was signed. Silicone oil was used as a tamponade in children or adults unwilling to adopt the strict face-down position, and for large macular holes.

All surgeries were performed under general anesthesia and by the same surgeon (H.G.). Standard three-port sclerotomies were done, followed by subtotal vitrectomy creating a posterior vitreous detachment if one was not already present. The suction mode of the vitrectomy cutter was used for this purpose.

The internal limiting membrane (ILM) was removed, using Eckardt end-gripping pick forceps, pinching the ILM about 2 disc diameters away from the foveal centre. Rhexis of the ILM was done leaving the foveal side till the end. The aim was to peel at least 2 disc diameters area of ILM $360^{\circ}$ around the hole. No dye was used to stain the ILM. In the last few years we used Triamcinolone acetonide for better ILM visualization during rhexis.

For the gas-treated eyes, a $20 \mathrm{~mL}$ syringe containing 14\% perfluoropropane gas was connected to the infusion cannula, and $17 \mathrm{~mL}$ was injected through the infusion cannula while gas and air were allowed to escape from the superior temporal sclerotomy site. The sclerotomy site was closed with 7-0 vicryl sutures. The infusion cannula was removed and the sclerotomy closed with 7-0 vicryl sutures. The conjunctiva was also closed with 7-0 vicryl sutures. Combined antibioticsteroid drops (tobramycin $0.3 \%$ with dexamethasone $0.1 \%$ ) and atropine drops were applied.

Postoperatively, combined antibiotic-steroid drops (tobramycin $0.3 \%$ with dexamethasone $0.1 \%$ ) were applied six times a day for 4 weeks and atropine drops were applied three times a day for 2 weeks.

For gas-treated eyes the patient was instructed to position his/her face down until $50 \%$ of the gas was absorbed, or for at least 2 weeks.

For silicone-treated eyes, the patient was instructed to position his/her face down as much as possible (at least 50\% of the day time) for 2 weeks.

Gas-treated patients were followed up the day after the operation, then after 1 week, then every month until the gas was absorbed, then every 2 months for at least 1 year after the last surgery. Silicone oil-treated eyes were followed up at least 1 year after silicone oil removal. Results were collected, tabulated, and statistically analyzed.

\section{Results}

Thirty-four cases were operated on during the study period. Twelve cases were excluded from the study due to the lack of at least 1 year of follow-up after the last surgical intervention, or due to the presence of associated rhegmatogenous retinal detachment. The 22 remaining cases were reviewed: nine cases $(40.9 \%)$ with silicone oil tamponade vs 13 cases $(59.1 \%)$ with $14 \% \mathrm{C}_{3} \mathrm{~F}_{8}$ gas tamponade. The age of the silicone oil-treated patients ranged from 10 to 40 years (mean $27.4 \pm 11.3$ years), while 
Table I Demographics

\begin{tabular}{|c|c|c|c|c|c|}
\hline \multirow[b]{2}{*}{ No } & \multicolumn{2}{|c|}{ Silicone oil group } & \multicolumn{2}{|c|}{$C_{3} F_{8}$ gas group } & \multirow[t]{2}{*}{$P$ value } \\
\hline & 9 & $40.9 \%$ & 13 & $59.1 \%$ & \\
\hline \multirow[t]{2}{*}{ Age } & Range & Mean \pm SD & Range & Mean \pm SD & $>0.05$ \\
\hline & $10-40$ & $27.4 \pm 11.3$ & $19-35$ & $26.54 \pm 5.68$ & \\
\hline Sex & Female (3) & Male (6) & Female (4) & Male (9) & $>0.05$ \\
\hline$\%$ & $33.3 \%$ & $66.7 \%$ & $30.77 \%$ & $69.23 \%$ & \\
\hline Follow-up & Range & Mean \pm SD & Range & Mean \pm SD & \\
\hline (months) & $12-18$ & $14.22 \pm 1.72$ & $12-24$ & $14.46 \pm 3.43$ & $>0.05$ \\
\hline
\end{tabular}

that of the gas-treated patients ranged from 19 to 35 years (mean $26.54 \pm 5.68$ years).

Female patients accounted for $33.3 \%$ (three of nine) of the silicone oil group and $30.77 \%$ (4 of 13) of the gas-treated group. The mean follow-up time in months for the silicone oil-treated group was $14.22 \pm 1.72$, ranging from 12 to 18 months after silicone oil removal. The mean follow-up time in months for the gas-treated group was $14.46 \pm 3.43$, ranging from 12 to 24 months (Table 1).

\section{Closure rates}

In the silicone oil-treated group, six of nine $(66.67 \%)$ of traumatic macular holes were sealed after the primary operation, while 12 of 13 (92.3\%) of the gas-treated group were sealed in a single operation. The overall primary closure rate was $81.8 \%$ (18 of 22). The nonclosure rate for the silicone oil group was $33.3 \%$ (three of nine). One case closed after a second operation in which proper removal of any epiretinal membranes was done, followed by $\mathrm{C}_{3} \mathrm{~F}_{8}$ injected as a tamponade. The other two cases could not be closed after a second operation, leaving a nonclosure rate of $22.2 \%$. The nonclosure rate for the gas-treated group was $7.7 \%$ (one of 13), in which the hole closed after a second operation in which removal of any epiretinal membranes was done and gas was re-injected as a tamponade. Including reoperations, the final rate of hole closure was 100\% (13 of 13) in gas-treated eyes and $77.8 \%$ (7 of 9) in the silicone oil-treated eyes (Table 2).

\section{Visual outcomes}

The pre-operative decimal visual acuity was 0.067 for the silicone oil group and 0.061 for the gas-treated group. The

Table 2 Closure rate

\begin{tabular}{|c|c|c|c|c|c|c|}
\hline \multirow[t]{2}{*}{ Hole closure } & \multicolumn{2}{|c|}{ Silicone oil } & \multicolumn{2}{|c|}{ Gas $\left(C_{3} F_{8}\right)$} & \multirow[t]{2}{*}{$x^{2}$} & \multirow[t]{2}{*}{$P$ value } \\
\hline & No. (9) & $\%$ & No. (13) & $\%$ & & \\
\hline Single operation & 6 & $66.7 \%$ & 12 & $92.3 \%$ & & \\
\hline 2nd operation & I & $11.1 \%$ & I & $7.7 \%$ & 3.385 & $>0.05$ \\
\hline Nonclosure & 2 & $22.2 \%$ & 0 & $0 \%$ & & \\
\hline
\end{tabular}

postoperative decimal visual acuity at 4 weeks was 0.126 for the silicone oil group and 0.255 for the gas-treated group. The postoperative decimal visual acuities at 6 months were 0.226 for the silicone oil group, while the postoperative decimal visual acuities at 6 months were 0.355 for the gas-treated group.

The postoperative decimal visual acuity at 1 year was 0.245 for the silicone oil group and 0.433 for the gas-treated group (Table 3).

\section{Adverse events}

Two cases (22.2\%) in the silicone oil group had permanent nonclosure of the macular hole. One case in the gas-treated group had a postoperative day 1 intraocular pressure of $48 \mathrm{mmHg}$ that was controlled by a combination of dorzolamide and timolol topical anti-glaucoma therapy twice daily for 2 weeks. None of the cases in the study developed postoperative retinal detachment or endophthalmitis. The occurrence of cataract was $44.4 \%$ (four of nine) for the silicone oil group and $46.15 \%$ (six of 13 ) for the gas-treated group.

\section{Discussion}

Twenty-two cases of traumatic macular hole repair, reviewed in a retrospective comparative study from November 1998 to August 2010, showed a higher closure rate for gas-treated eyes (92.3\%: 12 of 13) than for silicone oil tamponade (66.67\%: six of nine) in a single operation. The overall primary closure rate for traumatic macular holes was $81.8 \%$ (18 of 22). The final hole closure rate was $100 \%$ for the gas-treated group vs $77.8 \%$ for the silicone treated group. The lower rate of hole closure by

Table 3 Visual outcomes

\begin{tabular}{lllll}
\hline & Silicone oil & $\mathbf{G a s}\left(\mathbf{C}_{\mathbf{3}} \mathbf{F}_{\mathbf{8}}\right)$ & $\mathbf{T}$ & $\boldsymbol{P}$ value \\
\hline $\begin{array}{l}\text { Preoperative mean VA } \\
\text { Postoperative mean VA }\end{array}$ & 0.067 & 0.061 & 1.537 & $>0.05$ \\
$\quad$ & & & & \\
I month & 0.126 & 0.255 & 2.757 & $<0.05$ \\
6 months & 0.226 & 0.355 & 2.864 & $<0.05$ \\
I year & 0.245 & 0.433 & 3.983 & $<0.05$ \\
\hline
\end{tabular}

Notes: $P>0.05=$ not significant; $P<0.05=$ significant. Abbreviations: VA, visual acuity; T, Student's $t$-test. 


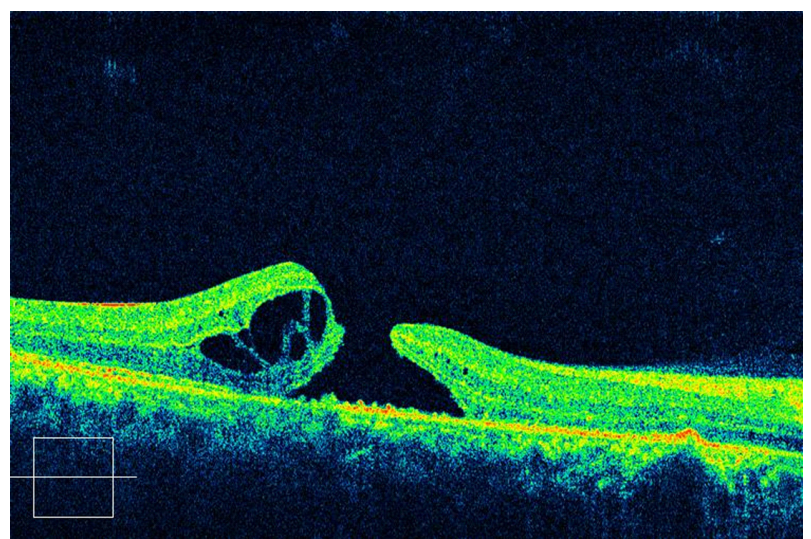

Figure I Preoperative OCT of traumatic macular hole with silicone oil tamponade.

silicone oil tamponade might be due to: the nature of the cases, as silicone oil was used for large traumatic macular holes; the lower surface tension of the silicone oil as compared with that of the gas; or patients' unreliability in maintaining a strict postoperative face-down position, particularly in children. ${ }^{25}$

Closure rates in this study were favorable compared with previous reports of idiopathic or myopic macular hole. This may be due to the fact that traumatic macular holes have better recovery rates than other types of macular holes. Healing may also be better in younger patients, and the early diagnosis of traumatic macular holes compared to other types of macular holes may help to improve the outcome. ${ }^{19-21}$

For silicone-treated eyes the final success rate $(77.8 \%)$ is less than that reported by Goldbaum et $\mathrm{al}^{7}$ who obtained an $83 \%$ silicone oil seal rate for idiopathic macular holes, and considerably less than the $97 \%$ reported previously by Pertile and Claes ${ }^{15}$ for idiopathic macular holes. Our silicone oil closure rate was higher than the $50 \%$ closure rate of idiopathic macular holes described by Voo et al. ${ }^{16}$ When comparing our final closure rates for gas-treated eyes $(100 \%)$ to previous studies, they were higher than the $58 \%$

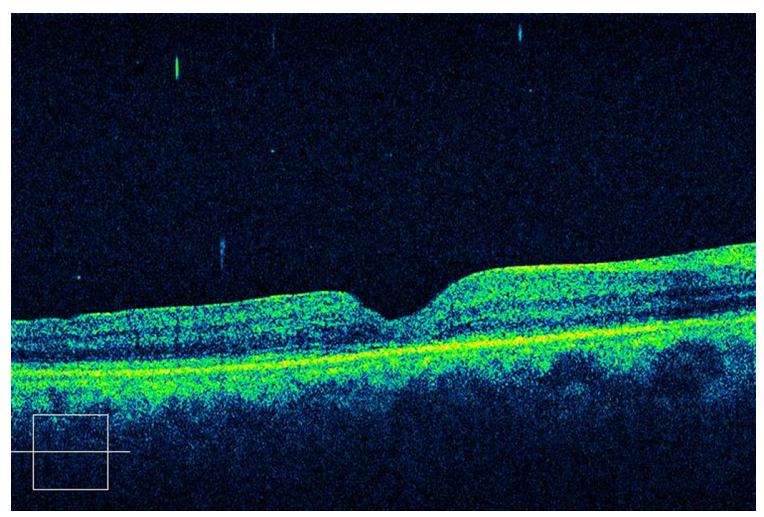

Figure 2 Postoperative OCT of traumatic macular hole with silicone oil tamponade after oil removal.

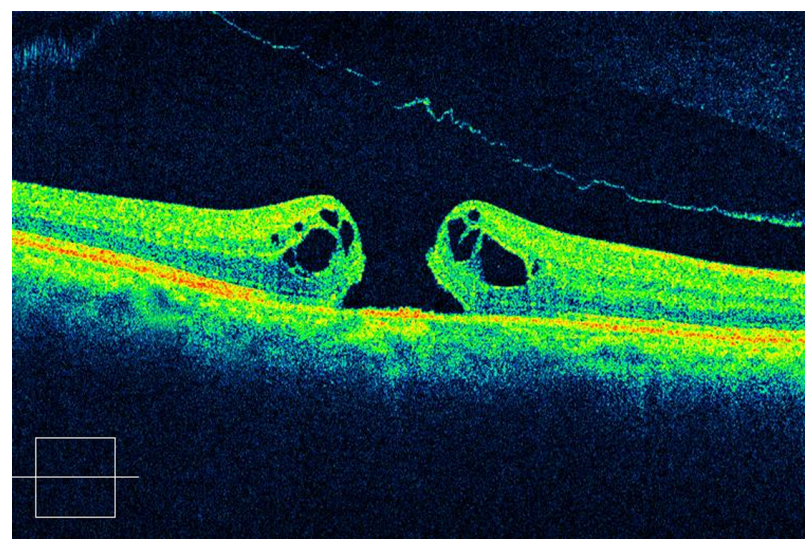

Figure 3 Preoperative OCT of traumatic macular hole with $\mathrm{C}_{3} \mathrm{~F}_{8}$ gas.

seal rate first described by Kelly and Wende $1^{17}$ and the $69 \%$ seal rate described by Freeman et al. ${ }^{18}$ This might be due to the fact that the macular holes in these studies were idiopathic and not traumatic macular holes as in our study.

The pre- and postoperative visual acuities were reviewed. The average pre-operative visual acuity was slightly worse in the silicone oil group compared to the gas-treated group. Each group showed a gradual improvement in visual acuities at 4 weeks, 6 months, and 1 year.

After 1 year the silicone oil group improved from 0.126 to 0.245 , while the gas-treated group improved from 0.255 to 0.433 . These findings correlate to a 3-line ETDRS visual acuity chart increase with silicone oil repair and a 4-line increase with gas repair. Goldbaum et $\mathrm{al}^{7}$ had a 3-4-line improvement with silicone oil closure of idiopathic macular holes but not in traumatic macular holes. The better visual outcomes in gas-treated eyes than in silicone-treated eyes may be due to the fact that silicone oil is in contact with the bare retinal pigment epithelium (RPE) and photoreceptors in macular hole surgery and has been found to be toxic to RPE and photoreceptors in previous studies. ${ }^{22-25}$

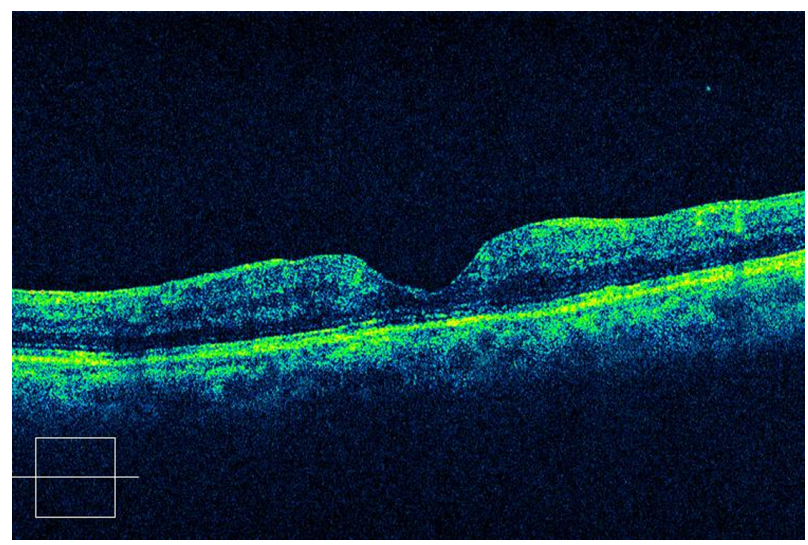

Figure 4 Postoperative OCT of traumatic macular hole with $\mathrm{C}_{3} \mathrm{~F}_{8}$ gas. 
In this study we concluded that gas tamponade is more successful in anatomical closure of traumatic macular holes than silicone oil tamponade. Eyes with traumatic macular holes surgically repaired with gas tamponade showed significant improvement in visual acuity compared with eyes treated with silicone oil tamponade.

\section{Disclosure}

The authors report no conflicts of interest in this work.

\section{References}

1. Ho AC, Guyer DR, Fine SL. Macular hole. Survey of Ophthalmology. 1998;42(5):393-416.

2. Judson PH, Yannuzzi LA. Macular Hole, In: Ryan S, editor. Retina. St Louis, MO: CV Mosby; 1989:229-242.

3. Saxena S, Melberg NS, Thomas MA. Surgical Management of Idiopathic Macular Hole. Ophthalmic Surg Lasers. 1996;27(7): 618-627.

4. Willis AW, Garcia-Cosio JF. Macular hole surgery. Comparison of longstanding versus recent macular holes. Ophthalmology. 1996;1031: $1811-1814$.

5. Ryan EH, Gilbert HD. Results of surgical treatment of recent onset full thickness idiopathic macular holes. Arch Ophthalmol. 1994;112(12): $1545-1553$.

6. Smiddy WE, Pimentel S, Williams GA. Macular hole surgery without using adjunctive additives. Ophthalmic Surg. Lasers. 1997;28(9): 713-717.

7. Goldbaum MH, McCuen BW, Hanneken AM, Burgess SK, Chen HH Silicone oil tamponade to seal macular holes without position restrictions. Ophthalmology. 1998;105(11):2140-2147.

8. Smiddy WE, Feuer W, Cordahi G. Internal limiting membrane peeling in macular hole surgery. Ophthalmology. 2001;108(8):1471-1476.

9. Margherio AR, Margherio RR, Hartzer M, Trese Mt, Williams GA, Ferrone PJ. Plasmin enzyme-assisted vitrectomy in traumatic pediatric macular holes. Ophthalmology. 1998;105(9):1617-1620.

10. Amari F, Ogino N, Matsumura M, Negi A, Yoshimura N. Vitreous surgery for traumatic macular holes. Retina. 1999;19(5):410-413.

11. Chow DR, Williams GA, Trese MT, Margherio RR, Ruby AJ, Ferrone PJ. Successful closure of traumatic macular holes. Retina. 1999;19(5): 405-409.
12. Johnson RN, McDonald HR, Lewis H, et al. Traumatic macular hole: observations, pathogenesis, and results of vitrectomy surgery. Ophthalmology. 2001;108(5):853-857.

13. Kuhn F, Morris R, Mester V, Witherspoon CD. Terson syndrome. Results of vitrectomy and the significance of vitreous hemorrhage in patients with subarachnoid hemorrhage. Ophthalmology. 1998;105(3): 472-477.

14. Hwang YS, Lai CC, Yang KJ, Chen TL. A rapid and successful treatment for airbag-related traumatic macular hole. Chang Gung Med J. 2001;24(8):530-535.

15. Pertile G, Claes C. Silicone oil vs gas for the treatment of full-thickness macular hole. Bull Soc Belge Ophtalmol. 1999;274:31-36.

16. Voo I, Siegner SW, Small KW. Silicone oil tamponade to seal macular holes. Ophthalmology. 2001;108(9):1516-1517.

17. Kelly NE, Wendel RT. Vitreous surgery for idiopathic macular holes. Results of a pilot study. Arch Ophthalmol. 1991;109(5):654-659.

18. Freeman WR, Azen SP, Kim JW, et al. Vitrectomy for the treatment of full-thickness stage 3 or 4 macular holes. Results of a multicentered randomized clinical trial. The Vitrectomy for Treatment of Macular Hole Study Group. Arch Ophthalmol. 1997;115(1):11-21.

19. Glaser BM, Michels RG, Kuppermann BD, Sjaarda RN, Pena RA. Transforming growth factor-beta 2 for the treatment of full thickness macular holes. A prospective randomized study. Ophthalmology. 1992;99(7):1162-1173.

20. Smiddy WE, Glaser BM, Thompson JT, et al. Transforming growth factor-beta 2 significantly enhances the ability to flatten the rim of subretinal fluid surrounding macular holes. Preliminary anatomic results of multi-center prospective randomized study. Retina. 1993;13(4): 296-301.

21. Thompson JT, Smiddy WE, Williams GA, et al. Comparison of recombinant transforming growth factor beta-2 and placebo as an adjunctive agent for macular hole surgery. Ophthalmology. 1998; 105(4):700-706.

22. Gonvers M, Hornung JP, de Courten C. The effect of silicone oil on the rabbit retina: histologic and ultrastructural study. Arch Ophthalmol. 1986;104(7):1057-1062.

23. Grey RH, Cringle SJ, Constable IJ. Fluorescein angiographic findings in three patients with long-term Intravitreal liquid silicone. $\mathrm{Br} J$ Ophthalmol. 1989;73(12):991-995.

24. Chan C, Okun E. The question of ocular tolerance to intravitreal liquid silicone. A long-term analysis. Ophthalmology. 1986;93(5):651-660.

25. Tafoya ME, Lambert HM, Vu L, Ding M. Visual outcomes of silicone oil versus gas tamponade for macular hole surgery. Semin Ophthalmol. 2003;18(3):127-131.
Clinical Ophthalmology

\section{Publish your work in this journal}

Clinical Ophthalmology is an international, peer-reviewed journal covering all subspecialties within ophthalmology. Key topics include: Optometry; Visual science; Pharmacology and drug therapy in eye diseases; Basic Sciences; Primary and Secondary eye care; Patient Safety and Quality of Care Improvements. This journal is indexed on

\section{Dovepress}

PubMed Central and CAS, and is the official journal of The Society of Clinical Ophthalmology (SCO). The manuscript management system is completely online and includes a very quick and fair peer-review system, which is all easy to use. Visit http://www.dovepress.com/ testimonials.php to read real quotes from published authors. 